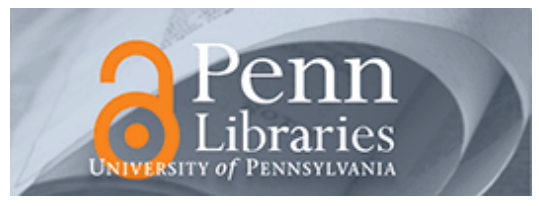

University of Pennsylvania ScholarlyCommons

6-2009

\title{
Modeling Expert Opinions on Food Healthfulness: A Nutrition Metric
}

Jolie M. Martin

John Beshears

Katherine L. Milkman

University of Pennsylvania

Max H. Bazerman

Lisa A. Sutherland

Follow this and additional works at: https://repository.upenn.edu/oid_papers

Part of the Human and Clinical Nutrition Commons, and the Other Food Science Commons

\section{Recommended Citation}

Martin, J. M., Beshears, J., Milkman, K. L., Bazerman, M. H., \& Sutherland, L. A. (2009). Modeling Expert Opinions on Food Healthfulness: A Nutrition Metric. Journal of the American Dietetic Association, 109 (6), 1088-1091. http://dx.doi.org/10.1016/j.jada.2009.03.009

This paper is posted at ScholarlyCommons. https://repository.upenn.edu/oid_papers/28

For more information, please contact repository@pobox.upenn.edu. 


\title{
Modeling Expert Opinions on Food Healthfulness: A Nutrition Metric
}

\author{
Abstract \\ Research during the last several decades indicates the failure of existing nutritional labels to substantially \\ improve the healthfulness of consumers' food/beverage choices. The present study aims to fill this void \\ by developing a nutrition metric that is more comprehensible to the average shopper. The healthfulness \\ ratings of 205 sample foods/beverages by leading nutrition experts formed the basis for a linear \\ regression that places weights on 12 nutritional components (ie, total fat, saturated fat, cholesterol, \\ sodium, total carbohydrate, dietary fiber, sugars, protein, vitamin A, vitamin C, calcium, and iron) to predict \\ the average healthfulness rating that experts would give to any food/beverage. Major benefits of the \\ model include its basis in expert judgment, its straightforward application, the flexibility of transforming \\ its output ratings to any linear scale, and its ease of interpretation. This metric serves the purpose of \\ distilling expert knowledge into a form usable by consumers so that they are empowered to make more \\ healthful decisions. \\ Disciplines \\ Human and Clinical Nutrition I Other Food Science
}


08-082

\title{
Modeling Expert Opinions on Food Healthiness: A Nutrition Metric
}

\author{
Jolie Mae Martin \\ John Leonard Beshears \\ Katherine Lyford Milkman \\ Max H. Bazerman \\ Lisa Sutherland
}

Copyright (C) 2008 by Jolie Mae Martin, John Leonard Beshears, Katherine Lyford Milkman, Max H. Bazerman, and Lisa Sutherland

Working papers are in draft form. This working paper is distributed for purposes of comment and discussion only. It may not be reproduced without permission of the copyright holder. Copies of working papers are available from the author. 


\title{
Modeling Expert Opinions on Food Healthiness:
}

\author{
A Nutrition Metric \\ Jolie M. Martin, John Beshears, Katy Milkman, Max Bazerman, Ph.D., \\ and Lisa Sutherland, Ph.D.
}

\begin{abstract}
Background

Research over the last several decades indicates the failure of existing nutritional labels to substantially improve the healthiness of consumers' food and beverage choices. The difficulty for policy-makers is to encapsulate a wide body of scientific knowledge in a labeling scheme that is comprehensible to the average shopper. Here, we describe our method of developing a nutrition metric to fill this void.
\end{abstract}

\section{Methods}

We asked leading nutrition experts to rate the healthiness of 205 sample foods and beverages, and after verifying the similarity of their responses, we generated a model that calculates the expected average healthiness 
rating that experts would give to any other product based on its nutrient content.

\section{Results}

The form of the model is a linear regression that places weights on 12 nutritional components (total fat, saturated fat, cholesterol, sodium, total carbohydrate, dietary fiber, sugars, protein, vitamin A, vitamin C, calcium, and iron) to predict the average healthiness rating that experts would give to any food or beverage. We provide sample predictions for other items in our database.

\section{Conclusions}

Major benefits of the model include its basis in expert judgment, its straightforward application, the flexibility of transforming its output ratings to any linear scale, and its ease of interpretation. This metric serves the purpose of distilling expert knowledge into a form usable by consumers so that they are empowered to make healthier decisions. 
Although standards of living are generally improving in the U.S. and other developed countries, health problems attributable to poor nutrition persist, due in part to consumers' inability to translate the dietary advice of nutrition experts into behavioral change. Citing the improvement of public health as a primary objective, numerous studies have highlighted the need for a nutritional scoring system that is both comprehensive in its coverage of food products and easily understood by consumers ${ }^{1-5}$. We aim to advance this objective by proposing a nutrition metric that is based on the current views of leading experts in the field and can be used to score any food or beverage for which several component nutrient quantities are known.

Regulatory efforts to improve nutritional labeling, such as the 1990 Nutrition Labeling and Education Act (NLEA), have had relatively limited impact in altering the behavior of individuals who were not already motivated to eat more healthily ${ }^{6,7}$. The complexity of processing nutritional information serves to limit the influence of point-ofpurchase labeling $^{8}$, especially in fast-food settings ${ }^{9}$ or when many options are available ${ }^{10}$. It may be especially difficult for consumers to interpret a food's contribution to overall diet $^{11}$ and to take into consideration the presence of favorable nutrients, given consumers’ established tendency to focus disproportionately on avoiding negative components ${ }^{6,12-13}$. Furthermore, the positive impact of more transparent labeling practices may be obscured by promotional efforts of manufacturers ${ }^{1,14}$. Not only can food advertising result in misleading generalization by consumers ${ }^{15}$, but it may even exacerbate negative behavior such as overeating in the case of "low fat" claims ${ }^{16}$.

Despite the limited success described above, there are several indications that nutritional labeling might have greater potential to assist consumers in making healthy 
food choices. For instance, direct comparability of nutrient information across options has been shown to induce more advantageous product selections ${ }^{13,17}$, and there is evidence suggesting that nutrition labeling schemes may be more effective when they are better adapted to a target audience or when they employ simple messages that promote taste as well as healthiness ${ }^{18}$. Given specific behavioral recommendations, subsequent decision-making is evaluated more favorably according to both consumers' own judgments and expert standards ${ }^{19}$. In addition, though marketers will likely continue attempts to promote the healthiness of their products regardless of true nutritional value, unbiased nutritional information may influence consumers' beliefs independently from these claims ${ }^{20,21}$, and consumer misperceptions may be mitigated by greater transparency about the net value of foods' nutritional components ${ }^{22}$.

Several recent studies have developed more detailed guidelines for accurate and effective nutritional labeling. Padberg ${ }^{3}$ finds a large degree of consensus amongst experts regarding the relative nutritional value of various foods, and calls for an Expert Rating System that appropriately weights various nutrient factors to summarize any food's nutritional value as part of a daily diet. Advancing this goal, Nijman et al. ${ }^{2}$ designed a Nutrition Score to characterize foods and beverages based on their levels of four detrimental components (trans fat, saturated fat, sugar, and sodium) whose generic benchmark levels have been established by scientific evidence. Unfortunately, their Final Product Nutrition Score fails to take into consideration the presence of favorable nutrients that also affect an item's healthiness. Perhaps the most thorough attempt at outlining desirable features of a nutritional profiling system is provided by Scarborough, Rayner, and Stockley ${ }^{5}$, advocating "a systematic, transparent and logical process” to categorize 
foods based on their nutritional composition. Scarborough, Boxer, Rayner, and Stockley ${ }^{23}$ evaluated each of eight existing nutrient profile models based on the correlations of their ratings with healthiness categorizations of 120 foods by nutrition professionals. We agree with the implicit logic that expert assessments are in some sense the most comprehensive embodiment of current scientific knowledge on nutrition, but we go one step further than Scarborough et al. by actually employing expert ratings to generate our model.

Our basic methodology was to survey leading nutrition experts about the healthiness of sample foods and beverages, to estimate the regression equation that best predicts expert ratings of foods using each item on a Nutrition Facts label as a predictor, and finally to analyze the applicability of this model to rating the healthiness of products outside our initial sample. In light of the goals of nutritional labeling described in the literature, we believe this approach has multiple benefits. First, it does not require experts to explicitly assign valuations to different nutrients, a procedure that would be prone to imprecision if experts are not accustomed to making direct numerical tradeoffs between nutrients. However, it still captures experts' judgments about the healthiness of different foods. Second, our model's output ratings can be transformed to any continuous distribution or categorization that is deemed optimal for conveying information to consumers in a particular context. Third, our model makes clear quantitative predictions about how experts would rate the overall healthiness of any item as part of a daily diet and can thus be used to compare nutritional values of foods and beverages either across or within product categories. 


\section{METHODS}

\section{Food/Beverage Sample}

A large online grocer provided us with a database containing nutritional information for over 15,000 unique food and beverage SKUs. Also listed in the database were the 205 categories used by the grocer to classify items and the unit sales of each item in 2005. In order to create a sample of foods representative of the items that consumers purchase most regularly but also covering a range of food/beverage types, we selected the most purchased item in each of the categories to comprise a sample of 205 foods and beverages for experts to rate. For each of these items, we collected any nutritional information that was missing from the grocer's database by searching for similar items on the USDA ${ }^{24}$ and NutritionData ${ }^{25}$ websites. In all cases, we were able to find very close matches in terms of product description and size.

\section{Expert Sample}

We requested participation from leading nutrition experts in rating the healthiness of the 205 sample foods/beverages described above. To mitigate bias in our responses, we contacted all 57 members of three groups that are widely recognized for their expertise in the study of nutrition: (1) Chairs of the top three schools of public health nutrition departments (Harvard University, Johns Hopkins University, and the University of North Carolina); (2) Directors of the eight U.S. Clinical Nutrition Research and 
Human Nutrition Centers; and (3) Directors of the 46 Coordinated Programs in Dietetics with accredited status from the American Dietetic Association. These experts - all of whom have earned doctoral degrees in fields related to nutrition - were each offered \$250 for their participation in our study, which required them to complete a one-hour online survey. The overall response rate was 23\% (13 participants).

\section{Data Collection}

Our web-based survey asked that participants rate the healthiness of each of the 205 foods/beverages in our sample when they are consumed (or used as ingredients) in the recommended serving size. We displayed the item name provided by the online grocer in its database, a picture of the item found online, and a nutrition label that we generated to look like a typical Nutrition Facts label shown on the package (see Appendix A for a survey screenshot). The label listed serving size, servings per container, calories per serving, calories from fat per serving, and the amount per serving of the following 12 components:

- Total fat (amount in grams and \% daily value)

- $\quad$ Saturated fat (amount in grams and \% daily value)

- Cholesterol (amount in milligrams and \% daily value)

- Sodium (amount in milligrams and \% daily value)

- Total carbohydrate (amount in grams and \% daily value)

- Dietary fiber (amount in grams and \% daily value)

- Sugars (amount in grams) 
- Protein (amount in grams)

- Vitamin A (\% daily value)

- Vitamin C (\% daily value)

- Calcium (\% daily value)

- Iron (\% daily value)

Participants rated each of the 205 items on an 11-point Likert scale from -5 ("very unhealthy”) to 5 (“very healthy”).

\section{RESULTS}

For each of the 13 experts surveyed, we ran an ordinary least squares (OLS) regression of the healthiness ratings they provided for the 205 sample foods/beverages on the 12 nutritional components of these items listed on a Nutrition Facts label (see Methods: Data Collection). Note that for components typically shown in both absolute amount and percentage of daily value on a Nutrition Facts label, we included only the absolute amount since the latter is redundant. For the same reason, we excluded from our set of predictor variables “calories per serving”, which is equal to $9 *$ fat grams $+4 *$ carbohydrate grams $+4 *$ protein grams $+7 *$ alcohol grams (alcohol was absent from the foods and beverages in our sample), and also excluded "calories from fat," which is equal to $9 *$ fat grams. It did not substantively change the predictive power of the models to replace the amounts of all nutritional components with their percentages of daily 
values or to include the predictor variables "calories per serving” and "calories from fat," so we will not report the results of those models.

The 13 regression models resulting from our analyses of individual experts’ survey responses indicate the implicit weightings (positive or negative) that each expert placed on various nutritional components in assessing the healthiness of sample foods and account for a considerable amount of the variance in each expert's sample ratings (average R-squared of 0.48; average adjusted R-squared of 0.45 ). We first used each expert's linear model to predict his/her ratings for the sample foods/beverages and compared them to the actual ratings given. The average difference between an expert's predicted rating and actual rating was 1.56 on the 11-point scale (which decreased slightly to 1.51 when we cut off predictions at the upper and lower endpoints of the ratings scale, which were -5 and 5 , respectively). Next, we used each expert's linear model to predict what his/her ratings would be for the remaining items in our database. Since the models were based on 12 label components shown on the Nutrition Facts label, we made predictions for just the subset of 9,393 items with these variables already available in our database.

To measure the similarity of the 13 experts' models for healthiness, we calculated Cronbach's alpha across the original sample ratings (0.95) and across the predictions for other items in the database (0.98). Cronbach's alpha is a measure of inter-rater reliability, and values that approach 1 like those reported above suggest that raters have very similar “underlying representations” of the construct they are rating (in this case, healthiness). Coupled with the only moderately high R-squared values of the raters' models, we can infer that the variation left unexplained by each rater's model was not caused by a large 
rating error but rather by the exclusion of predictors from the models that affect the healthiness of foods/beverages similarly for all experts. This indicates that the Nutrition Facts label may be missing some important unknown variables that experts agree affect the healthiness of foods and beverages. Despite this limitation on the variables available on for inclusion in our model, we argue that the high levels of correlation across experts’ judgments justifies the generation of a single linear model to predict the average expert opinion about the healthiness of a given food/beverage.

To generate such a model, we first averaged the ratings given by the 13 experts for each sample food/beverage. Across the 205 sample items, the average rating for experts had a mean of 0.30 and a standard deviation of 2.2 on the -5 to 5 scale. Next, we ran a robust regression to predict this average rating using the 12 nutritional components on each grocery's Nutrition Facts label as right-hand side variables. We calculated robust standard errors to allow for the possibility of heteroskedasticity. The results of our regression model to predict expert average ratings for a food/beverage are shown in Table 1. To summarize, the best predictor for the average rating that experts would give to any other food/beverage based on its nutritional components (to three significant digits) is:

Predicted rating $=0.710-0.0538 *$ fat $-0.423 *$ satfat $-0.00398 *$ chol $-0.00254 *$ sod

$$
\begin{aligned}
& -0.0300 * \text { carb }+0.561 * \text { fib }-0.0245 * \text { sug }+0.123 * \text { pro }+0.00562 * \text { vita } \\
& +0.0137 * \text { vitc }+0.0685 * \text { calc }-0.0186 * \text { iron }
\end{aligned}
$$


where the nutrient abbreviations correspond to the items listed in Table 1, in order, and units for all components must be specified as in Table 1. See Appendix B for example calculations of predicted ratings for two sample foods.

Using the model to predict ratings for all 205 foods/beverages in our sample, we found that the output predictions had an average absolute difference of 1.06 and a correlation of 0.791 with the actual average ratings used as inputs (which improved slightly to an average absolute difference of 1.03 and correlation of 0.805 when predictions were cut off at the endpoints of our 11-point scale). The model's R-squared of 0.626 suggests that it captures almost two-thirds of the variance in experts' average ratings of foods and beverages.

We next used the model to predict the average ratings that would be given by the population of experts to the other 9,393 foods/beverages in our database based on the 12 predictor variables on a Nutrition Facts label. Upon inspection, the predictions seemed very reasonable. The average predictions across items within each of the 205 product categories are shown in Appendix C, ordered from highest average rating to lowest average rating. To give some sense of the usefulness of comparison within a single category, the predictions for all items listed under “All Other Salty Snacks” are shown in Appendix D, ordered from highest predicted rating to lowest predicted rating.

Although the valence of impact that most nutrients have on the healthiness of a food may be common knowledge even to lay consumers, the clear contribution of our model is an assignment of a magnitude weighting to each nutritional component of a food/beverage. This allows the separate effects of each nutritional component to be isolated without compromising the ability to summarize their combined impact in a single 
metric. Indeed, the model summarized in Table 1 demonstrates that some nutritional components have significant positive effects on a food's healthiness while others have significant negative effects, implying that previous models focusing solely on either positive or negative nutrients omitted critical information that experts take into account when rating a food's healthiness. While we have necessarily made some tradeoffs between the explanatory power of our model and its simplicity, we believe that our model includes the most important inputs to the healthiness judgments of nutrition experts as a result of its reliance on the nutrition inputs included on all Nutrition Facts labels.

\section{DISCUSSION}

By obtaining experts' ratings for a broad sample of foods and beverages, we have derived a comprehensive model for rating a food or beverage's healthiness that meets many of the desired criteria for such a metric. First and foremost, our method of sampling both experts and foods was deliberately transparent to eliminate as much bias as possible from our results. The decision to generate a model of a food's healthiness based on average expert ratings was validated by a high level of agreement across experts regarding the healthiness of sample items. In addition, our metric has a straightforward interpretation of providing the predicted average expert rating that a food or beverage would receive based on its Nutrition Facts label. Finally, the fact that our model's output ratings lie along a one-dimensional numerical spectrum allows for ease of interpretation, 
suggesting these ratings could be understood by consumers making decisions about what foods and beverages to buy and consume.

We foresee several possible applications for our model. Similar to the work of Scarborough, Boxer, Rayner, and Stockley ${ }^{23}$, the predicted ratings of our model (or the actual sample ratings for that matter) could be correlated with ratings produced by other, competing metrics to determine whether these other measures actually incorporate the knowledge of experts into their proposed nutrient weightings. More importantly, we hope that our model will be used to generate healthiness ratings for foods and beverages that could be displayed on or near product labels, allowing consumers to make more informed choices about what products to purchase and consume. To this end, we plan to conduct controlled experiments to test the extent to which the output of our model helps consumers to make decisions that are more closely aligned with the recommendations of nutrition experts. 


\section{REFERENCES}

1. Asam, Edward H., and Louis P. Bucklin. Nutrition Labeling for Canned Goods: A Study of Consumer Response. Journal of Marketing, 1973;37(2):32-7.

2. Nijman, C. A. J., I. M. Zijp, A. Sierksma, A. J. C. Roodenburg, R. Leenen, C. van den Kerkhoff, J. A.Weststrate, and G. W. Meijer. A Method to Improve the Nutritional Quality of Foods and Beverages Based on Dietary Recommendations. European Journal of Clinical Nutrition, 2006:1-11.

3. Padberg, D. I. Nutritional Labeling as a Policy Instrument. American Journal of Agricultural Economics, 1992;74(5):1208-12.

4. Rothschild, Michael L. Carrots, Sticks, and Promises: A Conceptual Framework for the Management of Public Health and Social Issue Behaviors. Journal of Marketing, 1999;63:24-37.

5. Scarborough, Peter, Mike Rayner, and Lynn Stockley. Developing Nutrient Profile Models: A Systematic Approach. Public Health Nutrition, 2007;10(4):330-6.

6. Balasubramanian, Siva K., and Catherine Cole. Consumers' Search and Use of Nutrition Information: The Challenge and Promise of the Nutrition Labeling and Education Act. Journal of Marketing, 2002;66(3):112-27.

7. Keller, Scott B., Mike Landry, Jeanne Olson, Anne M. Velliquette, Scot Burton, and J. Craig Andrews. The Effects of Nutrition Package Claims, Nutrition Facts Panels, and Motivation to Process Nutrition Information on Consumer Product Evaluations. Journal of Public Policy and Marketing, 1997;16(2):256-69. 
8. Caswell, Julie A., and Daniel I. Padberg. Toward a More Comprehensive Theory of Food Labels. American Journal of Agricultural Economics, 1992;74(2):460-8.

9. McNeal, James U., Donald E. Stem, Jr., and Carol S. Nelson. Consumers' Nutritional Ratings of Fast-Food Meals. Journal of Consumer Affairs, 1980;14(1):165-79.

10. Seymour, Jennifer D., Amy Lazarus Yaroch, Mary Serdula, Heidi Michels Blanck, and Laura Kettel Khan. Impact of Nutrition Environmental Interventions on Point-ofPurchase Behavior in Adults: A Review. Preventive Medicine, 2004;39:S108-36.

11. Cowburn, Gill, and Lynn Stockley. Consumer Understanding and Use of Nutrition Labelling: A Systematic Review. Public Health Nutrition, 2005;8(1):21-8.

12. Garretson, Judith A., and Scot Burton. Effects of Nutrition Facts Panel Values, Nutrition Claims, and Health Claims on Consumer Attitudes, Perceptions of DiseaseRelated Risks, and Trust. Journal of Public Policy and Marketing, 2000;19(2):213-27.

13. Russo, J. Edward, Richard Staelin, Catherine A. Nolan, Gary J. Russell, and Barbara A. Metcalf. Nutrition Information in the Supermarket. Journal of Consumer Research, 1986;13(1):48-70.

14. Tyebjee, Tyzoon T. Affirmative Disclosure of Nutrition Information and Consumers' Food Preferences: A Review. Journal of Consumer Affairs, 1979;13(2):206-35.

15. Andrews, J. Craig, Richard G. Netemeyer, and Scot Burton. Consumer Generalization of Nutrient Content Claims in Advertising. Journal of Marketing, 1998;62(4):62-75.

16. Wansink, Brian, and Pierre Chandon. Can 'Low-Fat' Nutrition Labels Lead to Obesity? Journal of Marketing Research, 2006;43:605-17. 
17. Muller, Thomas E. Structural Information Factors Which Stimulate the Use of Nutrition Information: A Field Experiment. Journal of Marketing Research, 1985;22(2):143-57.

18. Holdsworth, M., and C. Haslam. A Review of Point-of-Choice Nutrition Labelling Schemes in the Workplace, Public Eating Places and Universities. Journal of Human Nutrition and Dietetics, 1998;11:423-45.

19. Moorman, Christine. The Effects of Stimulus and Consumer Characteristics on the Utilization of Nutrition Information. Journal of Consumer Research, 1990;17(3):36274.

20. Ford, Gary T., Manoj Hastak, Anusree Mitra, and Debra Jones Ringold. Can Consumers Interpret Nutrition Information in the Presence of a Health Claim? A Laboratory Investigation. Journal of Public Policy and Marketing, 1996;15(1):16-27.

21. Kozup, John C., Elizabeth H. Creyer, and Scot Buiion. Making Healthful Food Choices: The Influence of Health Claims and Nutrition Information on Consumers' Evaluations of Packaged Food Products and Restaurant Menu Items. Journal of Marketing, 2003;67:19-34.

22. Mazis, Michael B., and Mary Anne Raymond. Consumer Perceptions of Health Claims in Advertisements and on Food Labels. Journal of Consumer Affairs, 1997;31(1):10-26.

23. Scarborough, Peter, Anna Boxer, Mike Rayner, and Lynn Stockley. Testing Nutrient Profile Models Using Data from a Survey of Nutrition Professionals. Public Health Nutrition, 2007;10(4):337-45. 
24. United States Department of Agriculture Food and Nutrient Database for Dietary Studies. (Accessed Summer, 2007, at http://www.ars.usda.gov/Services/docs.htm?docid=12089.)

25. NutrtionData.com. (Accessed Summer, 2007, at http://www.nutritiondata.com.) 


\section{TABLES AND FIGURES}

Table 1 - Regression results for average expert rating of 205 sample foods/beverages

\begin{tabular}{|l|l|}
\hline & Coefficient \\
\hline (Intercept) & $0.710 * * *$ \\
& $(0.207)$ \\
\hline Total fat (g) & -0.0538 \\
& $(0.0414)$ \\
\hline Saturated fat (g) & $-0.423 * * *$ \\
& $(0.0944)$ \\
\hline Cholesterol (mg) & -0.00398 \\
& $(0.00330)$ \\
\hline Sodium (mg) & $-0.00254 * * *$ \\
& $(0.000445)$ \\
\hline Total carbohydrate (g) & $-0.0300 * *$ \\
& $(0.0110)$ \\
\hline Fiber (g) & $0.561 * * *$ \\
& $(0.109)$ \\
\hline Sugar (g) & -0.0245 \\
& $(0.0190)$ \\
\hline Protein (g) & $0.123 * * *$ \\
& $(0.0222)$ \\
\hline Vitamin A (\%DV) & $0.00562 *$ \\
& $(0.00234)$ \\
\hline Vitamin C (\%DV) & $0.0137 * * *$ \\
& $(0.00399)$ \\
\hline Calcium (\%DV) & $0.0685 * * *$ \\
& $(0.0137)$ \\
\hline Iron (\%DV) & -0.0186 \\
& $(0.0186)$ \\
\hline
\end{tabular}

Significance codes: $* * * \mathrm{p}<0.001 * * \mathrm{p}<0.01 * \mathrm{p}<0.05$ 


\section{APPENDIX A}

Survey screenshot

Food/Beverage 1 of 205

\section{Black Pearls Ripe Olives Sliced}

\begin{tabular}{|lr}
\hline Nutrition Facts \\
Serving size 2 TBSP \\
Servings per container 4 \\
\hline Amount per serving \\
\hline Calories 25 & Calories from fat 25 \\
\hline & $\%$ Daily Value \\
\hline Total Fat $2.5 \mathrm{~g}$ & $4 \%$ \\
\hline Saturated Fat $0 \mathrm{~g}$ & $0 \%$ \\
\hline Cholesterol $0 \mathrm{mg}$ & $0 \%$ \\
\hline Sodium $125 \mathrm{mg}$ & $5 \%$ \\
\hline Total Carbohydrate $1 \mathrm{~g}$ & $0 \%$ \\
\hline Dietary Fiber $0 \mathrm{~g}$ & $0 \%$ \\
\hline Sugars $0 \mathrm{~g}$ & \\
\hline Protein $0 \mathrm{~g}$ & \\
\hline Vitamin A 0 $0 \%$ & Iron $0 \%$ \\
\hline Calcium $0 \%$ & \\
\hline
\end{tabular}

How would you rate this food/beverage on a scale from $-5=$ "very unhealthy" to $5=$ "very healthy"?

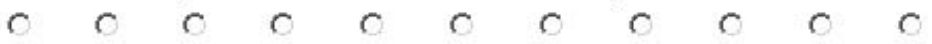

$\begin{array}{lllllllllll}-5 & -4 & -3 & -2 & -1 & 0 & 1 & 2 & 3 & 4 & 5\end{array}$




\section{APPENDIX B}

Example calculations of predicted rating for two sample foods (Morningstar Farms Meatless Breakfast Patties, which received a relatively high actual average rating of 1.69, and Boston Market Double Chocolate Pudding, which received a relatively low actual average rating of -1.77$)$ :

Predicted rating for one Morningstar Farms Meatless Breakfast Patty

$$
\begin{aligned}
= & 0.710-0.0538 * 3-0.423 * 0.5-0.00398 * 0-0.00254 * 270-0.0300 * 3 \\
& +0.561 * 2-0.0245 * 1+0.123 * 10+0.00562 * 0+0.0137 * 0+0.0685 * 0 \\
& -0.0186 * 10 \\
= & 1.70
\end{aligned}
$$

Predicted rating for one 4oz. serving of Boston Market Double Chocolate Pudding

$$
\begin{aligned}
= & 0.710-0.0538 * 7-0.423 * 4.5-0.00398 * 40-0.00254 * 170-0.0300 * 27 \\
& +0.561 * 1-0.0245 * 22+0.123 * 4+0.00562 * 1+0.0137 * 3+0.0685 * 10 \\
& -0.0186 * 3 \\
= & -1.78
\end{aligned}
$$




\begin{abstract}
APPENDIX C
The average model predictions across items within each of the 205 product categories, ordered from highest average predicted rating to lowest average predicted rating.
\end{abstract}

\begin{tabular}{ll} 
& Average Predicted \\
Category Name & Rating \\
\hline DRIED BEANS (GENERIC) & 7.87 \\
NATURAL SUPPLEMENTS & 7.86 \\
CITRUS (FRESH) & 3.68 \\
INSTANT BREAKFAST & 3.67 \\
NUTRITIONAL FOODS/BEVRGE & 3.37 \\
SKIM MILK & 3.35 \\
DIET AIDS & 3.34 \\
SPINACH (FRESH) & 3.26 \\
ORGANIC FRUITS (FRESH) & 3.26 \\
BERRIES (FRESH) & 3.17 \\
SOY MILK & 3.11 \\
BAKED BEANS (GENERIC) & 2.91 \\
ORGANIC VEGETABLES(FRESH) & 2.69 \\
ALL OTHR FRESH VEGETABLES & 2.67 \\
MEAT SUBSTITUTE (FROZEN) & 2.37 \\
POTATOES/ONIONS (FRESH) & 2.32 \\
ALL OTHER RFG BEVRGE & 2.12 \\
PEARS (FRESH) & 2.07 \\
MILK SUBSTITUTES & 2.07 \\
CUCUMBERS/PICKLES (FRESH) & 2.06 \\
PKGED SALAD MIX (FRESH) & 1.83 \\
ALL OTHER VEGETABLES (GENERIC) & 1.79 \\
STONE FRUITS (FRESH) & 1.79 \\
LETTUCE (FRESH) & 1.77 \\
BAGELS & 1.70 \\
HOT CEREAL/OATMEAL & 1.67 \\
JUICE (RFG) & 1.66 \\
FLOURS/CORNMEAL & 1.63 \\
BANANAS (FRESH) & 1.61 \\
ORGANIC MILK & 1.58 \\
ALL OTHER FRESH FRUIT & 1.57 \\
CHILI (GENERIC) & 1.56 \\
LAMB/VEAL (FRESH) & 1.54 \\
TUNA (GENERIC) & 1.50 \\
FISH (FRESH) & 1.49 \\
ROLLS/BUNS (FRESH) & 1.43 \\
BREAD LOAVES & 1.41 \\
PASTA (GENERIC) & 1.39 \\
PHE &
\end{tabular}




\begin{tabular}{|c|c|}
\hline RTE CEREAL & 1.39 \\
\hline TOMATOES (FRESH) & 1.39 \\
\hline SOY/RICE DRINKS (GENERIC) & 1.35 \\
\hline CONDNSD/EVAP/PWDRD MILK & 1.27 \\
\hline ALL OTHER BAKERY (COMM.) & 1.27 \\
\hline ALL OTHER FRESH MEAT & 1.27 \\
\hline BAGELS (FRESH) & 1.19 \\
\hline STANDARD MILK & 1.16 \\
\hline RICOTTA CHEESE & 1.13 \\
\hline APPLESAUCE (GENERIC) & 1.11 \\
\hline ALL OTHER MILK & 1.09 \\
\hline BAKING NUTS & 1.08 \\
\hline BREAD (FRESH) & 1.06 \\
\hline TOMATO PRODUCTS (GENERIC) & 1.04 \\
\hline BUNS/ROLLS & 0.84 \\
\hline SNACK NUTS/SEEDS & 0.83 \\
\hline LAMB/VEAL (FROZEN) & 0.80 \\
\hline SALAD TOPPINGS & 0.77 \\
\hline HERBS (FRESH) & 0.76 \\
\hline COTTAGE CHEESE & 0.74 \\
\hline ALL OTHER FRUIT (GENERIC) & 0.73 \\
\hline WATER - CARBONATED & 0.72 \\
\hline WATER - NON-CARBONATED & 0.72 \\
\hline WHOLE COFFEE BEANS & 0.71 \\
\hline COOKING SPRAYS & 0.71 \\
\hline APPLES (FRESH) & 0.70 \\
\hline TURKEY (FRESH) & 0.70 \\
\hline STRING CHEESE & 0.66 \\
\hline SUGAR SUBSTITUTES & 0.66 \\
\hline VINEGARS & 0.62 \\
\hline DRIED FRUIT & 0.60 \\
\hline DIET SODA & 0.60 \\
\hline HOT/INSTANT TEA & 0.59 \\
\hline PIE/PASTRY FILLINGS & 0.58 \\
\hline BRKFST BARS/GRANOLA SNCKS & 0.57 \\
\hline SHELLFISH (FROZEN) & 0.57 \\
\hline TURKEY (FROZEN) & 0.56 \\
\hline MUSTARD & 0.54 \\
\hline POPCORN (UNPOPPED) & 0.52 \\
\hline DRINKS (RFG) & 0.51 \\
\hline ALL OTHER DRIED BREAD & 0.51 \\
\hline COFFEE CREAMER (FROZEN) & 0.49 \\
\hline RICE/CORN CAKES & 0.46 \\
\hline SALSA & 0.45 \\
\hline COOKING WINES & 0.45 \\
\hline TORTILLA CHIPS & 0.44 \\
\hline JUICE (FROZEN) & 0.42 \\
\hline SEAFOOD ALL OTHER (GENERIC) & 0.39 \\
\hline SALTINE CRACKERS & 0.38 \\
\hline HOT CHOCOLATE MIX & 0.37 \\
\hline
\end{tabular}




\begin{tabular}{|c|c|}
\hline ICE CREAM CONES & 0.33 \\
\hline PANCAKE/WAFFLE MIX & 0.33 \\
\hline GUM \& MINTS & 0.33 \\
\hline GELATIN SNACKS (RFG) & 0.32 \\
\hline INSTANT POTATOES & 0.30 \\
\hline GELATIN MIXES & 0.29 \\
\hline PEANUT BUTTER & 0.28 \\
\hline SLICED CHEESE & 0.27 \\
\hline ALL OTHER PACKAGED DELI & 0.27 \\
\hline SHREDDED/GRATED CHEESE & 0.27 \\
\hline SUGAR & 0.26 \\
\hline OLIVE/PICKLE/PEPPERS (GENERIC) & 0.23 \\
\hline POPCORN (POPPED) & 0.23 \\
\hline DELI MEATS (BULK) & 0.22 \\
\hline BAGELS (FROZEN) & 0.18 \\
\hline STUFFING/BRDCRMBS/CROUTNS & 0.18 \\
\hline PUDDING MIXES & 0.13 \\
\hline CHICKEN (FRESH) & 0.11 \\
\hline KETCHUP & 0.10 \\
\hline BREAD MIXES & 0.10 \\
\hline JAM/JELLIES/SPREADS & 0.08 \\
\hline SNACK/SPECIALTY CRACKERS & 0.02 \\
\hline COFFEE CREAMER (RFG) & 0.00 \\
\hline INSTANT COFFEE & -0.01 \\
\hline SNACK MIXES & -0.02 \\
\hline PRETZELS & -0.03 \\
\hline RTD TEA & -0.04 \\
\hline ALL OTHER SALTY SNACKS & -0.07 \\
\hline ALL OTHER CONDIMENTS & -0.07 \\
\hline DIPS (GENERIC)/DIP MIX & -0.11 \\
\hline CORN CHIPS/SNACKS & -0.13 \\
\hline ALL OTHER CRACKERS & -0.13 \\
\hline GRAHAM CRACKERS & -0.14 \\
\hline CONDENSED SOUP & -0.17 \\
\hline ALL OTHER FROZEN MEAT & -0.19 \\
\hline HONEY & -0.19 \\
\hline RICE/COUSCOUS & -0.21 \\
\hline MARSHMALLOWS & -0.21 \\
\hline COFFEE DRINKS (RTD) & -0.21 \\
\hline RTE SOUP & -0.27 \\
\hline DELI CHEESE (BULK) & -0.27 \\
\hline PASTA MIXES & -0.28 \\
\hline GROUND COFFEE & -0.28 \\
\hline DOUGH (FROZEN) & -0.29 \\
\hline MAYO/SANDWICH SPREADS & -0.31 \\
\hline CHUNK CHEESE & -0.32 \\
\hline ISOTONIC DRINKS & -0.34 \\
\hline ALL OTHER CHEESE & -0.34 \\
\hline CHICKEN (FROZEN) & -0.38 \\
\hline POTATO CHIPS & -0.38 \\
\hline
\end{tabular}




\begin{tabular}{|c|c|}
\hline COFFEE CREAMER (GENERIC) & -0.39 \\
\hline HALF \& HALF/CREAM & -0.39 \\
\hline ALL OTHER FROZEN BREAD & -0.41 \\
\hline MARGARINE/SPREADS & -0.43 \\
\hline GELATIN SNACKS (GENERIC) & -0.43 \\
\hline DELI PREPACK & -0.44 \\
\hline BBQ SAUCE/STEAK SAUCE & -0.49 \\
\hline FISH (FROZEN) & -0.52 \\
\hline ALL OTHER FRZN SEAFOOD & -0.53 \\
\hline BROWNIES (FRESH) & -0.54 \\
\hline PUDDING SNACKS (RFG) & -0.59 \\
\hline BROWNIE/COOKIE/MUFFIN MIX & -0.60 \\
\hline DRINKS (FROZEN) & -0.62 \\
\hline MUFFINS (FRESH) & -0.62 \\
\hline FRZN WAFFLE/PANCAKE/TOAST & -0.64 \\
\hline RICE/COUSCOUS MIXES & -0.66 \\
\hline ALL OTHR PREPD FOODS (GENERIC) & -0.67 \\
\hline PUDDING SNACKS (GENERIC) & -0.72 \\
\hline ALL OTHER FRESH SEAFOOD & -0.74 \\
\hline HAM/PORK (FRESH) & -0.76 \\
\hline ALL OTHER COOKING OILS & -0.77 \\
\hline SOUP MIXES & -0.84 \\
\hline CANDY NON-CHOCOLATE & -0.84 \\
\hline DELI PREPARED SIDE DISHES & -0.85 \\
\hline OLIVE OIL & -0.89 \\
\hline DELI SALADS (BULK) & -0.90 \\
\hline DONUTS (FRESH) & -0.91 \\
\hline MAC \& CHEESE MIXES & -0.97 \\
\hline CHEESE SNACKS & -1.00 \\
\hline REGULAR SODA & -1.02 \\
\hline ICE CREAM TOPPINGS & -1.02 \\
\hline BROTH/BOULLION & -1.04 \\
\hline SALAD DRESSINGS & -1.04 \\
\hline ALL OTHR DRY DINNER MIXES & -1.11 \\
\hline HAM/PORK (FROZEN) & -1.15 \\
\hline COOKIES (FRESH) & -1.18 \\
\hline SHORTENING/LARD & -1.20 \\
\hline TOASTER/TART PASTRIES & -1.28 \\
\hline FROZEN NOVELTIES & -1.33 \\
\hline BEEF (FRESH) & -1.34 \\
\hline ALL OTHER ICE CREAM & -1.36 \\
\hline CANNED PASTA (GENERIC) & -1.38 \\
\hline ALL OTHER FROZEN BEVRGE & -1.41 \\
\hline CREAM CHEESE & -1.42 \\
\hline ALL OTHER BAKING MIXES & -1.43 \\
\hline BREAKFAST SYRUP & -1.44 \\
\hline BAKING CHOC/MORSL/COCONUT & -1.47 \\
\hline DELI PREPARED ENTREES & -1.48 \\
\hline FROSTING & -1.63 \\
\hline SAUSAGE (FROZEN) & -1.67 \\
\hline
\end{tabular}




$\begin{array}{ll}\text { ALL OTHER FRESH DELI } & -1.70 \\ \text { DELI PREPARED DESSERTS } & -1.78 \\ \text { MEAT (GENERIC) } & -1.87 \\ \text { ICE CREAM/SORBET/FZN YGRT } & -1.97 \\ \text { CAKE MIXES } & -2.02 \\ \text { SWEET GOODS } & -2.05 \\ \text { BACON/BREAKFAST SAUSAGE } & -2.09 \\ \text { BEEF (FROZEN) } & -2.26 \\ \text { CAKES (FRESH) } & -2.29 \\ \text { CANDY CHOCOLATE } & -2.40 \\ \text { ALL OTHER FRZN BREAKFAST } & -2.46 \\ \text { BUTTER } & -2.56 \\ \text { SAUSAGE (FRESH) } & -2.70 \\ \text { HOT DOGS/SAUSAGE/BRATS } & -2.84 \\ \text { PIES (FRESH) } & -2.86 \\ \text { ALL OTHER FRESH BAKERY } & -3.53 \\ \text { PRE-MADE LUNCH PACKS } & -3.65\end{array}$




\begin{abstract}
APPENDIX D
The model predictions for all items listed under the category “All Other Salty Snacks,” ordered from highest predicted rating to lowest predicted rating.
\end{abstract}

Food in the "All Other Salty Snacks" Category Predicted Rating

Guiltless Gourmet Guiltless Carbs Chips Three Pepper 2.97 Guiltless Gourmet Guiltless Carbs Chips Southwestern Ranch 2.84 Guiltless Gourmet Guiltless Carbs Chips Salsa Verde 2.84 Snyder's of Hanover EatSmart Soy Teins Parmesan, Garlic \& Olive Oil 2.29 Snyder's of Hanover EatSmart Soy Teins Tomato, Romano \& Olive Oil 2.24 Glenny's Soy Crisps Barbeque Low Fat $\quad 1.96$ Glenny's Soy Crispy Wispys White Cheddar $\quad 1.65$ Glenny's Soy Crisps Light Low Fat Salted 1.51 Calbee Snack Salad Snapea Crisps Original $\quad 1.25$

$\begin{array}{lr}\text { Calbee Snack Salad Snapea Crisps Caesar } & 1.16\end{array}$

$\begin{array}{ll}\text { Terra Vegetable Chips Exotic } & 1.13\end{array}$

Cedar's Hommus Pita Scoopers Plain $\quad 0.73$

Cedar's Hommus Pita Scoopers Garlic $\quad 0.58$

Frito-Lay Sun Chips French Onion $\quad 0.42$

Frito-Lay Sun Chips Original $\quad 0.39$

Snyder's of Hanover EatSmart Veggie Crisps Sundried Tomato \& Pesto Natural $\quad 0.37$

Frito-Lay Sun Chips French Onion $\quad 0.35$

Frito Lay Sun Chips Cheddar Flavor $\quad 0.28$

Frito-Lay Sun Chips Harvest Cheddar $\quad 0.27$

Frito-Lay Sun Chips Original $\quad 0.23$

$\begin{array}{ll}\text { Oberto Beef Jerky } & 0.23\end{array}$

Roberts American Gourmet Pirates Booty Puffed Rice Corn Snack Caramel 0.08

Snyder's of Hanover EatSmart Veggie Crisps 100\% Natural 0.05

$\begin{array}{ll}\text { Oberto Beef Jerky Teriyaki } & 0.05\end{array}$

Oberto Beef Jerky Barbecue $\quad-0.03$

Utz Lunch Box Snack Packs Regular 12 Count $\quad-0.31$

Utz Mega Variety Snack Pack 1 oz ea - 42 ct $\quad-0.31$

Snyder's of Hanover EatSmart Veggie Crisps Jalapeno \& Cheddar 100\% Natural $\quad-0.31$

Funyuns 12-Sack $\quad-0.32$

Wild Oats Natural Rice Snacks Oriental $\quad-0.36$

Wild Oats Natural Sesame Sticks $\quad-0.50$

Frito-Lay Munchies Snack Mix $\quad-0.52$

Osem Bamba Snacks Peanut $\quad-0.72$

Nature's Promise Vegetable Chips All Natural $\quad-0.84$

Slim Jim Beef Jerky - 4 ct $\quad-0.89$

Nature's Promise Vegetable Sticks All Natural $\quad-0.93$

French's Potato Sticks Original $\quad-0.98$

Osem Bissli Snacks Barbecue $\quad-0.99$ 
Osem Bissli Snacks Taco

Osem Bissli Snacks Smokey

Osem Bissli Snacks Pizza

$-1.28$

French's Potato Sticks Original

$-1.59$

Slim Jim Smoked Snacks Spicy - 15 ct

$-2.55$

Slim Jim Smoked Snacks Mild - 15 ct

$-2.55$

Jays O-KE-DOKE Corn Puffs

$-2.61$

Slim Jim Smoked Snacks Spicy - 5 ct

$-4.09$

Slim Jim Smoked Snacks Mild - 5 ct

$-4.09$ 